The inf I uence of the hot wi re temperat ure on the crystallization of $\mu \mathrm{C}-\mathrm{Si}: \mathrm{H}$ films prepared by hot wi re-assi st ed- ECR CVD

\begin{tabular}{|l|l|}
\hline 著者 & $\begin{array}{l}\text { Li Yi ng, Zhong L. Zhi , Hua Chen Guang, Kuneda } \\
\text { M nor u }\end{array}$ \\
\hline $\begin{array}{l}\text { j our nal or } \\
\text { publ i cat i on ti t l e }\end{array}$ & $\begin{array}{l}\text { Nat er i al s Resear ch Soci et y Symposi um } \\
\text { Proceedi ngs }\end{array}$ \\
\hline vol une & 910 \\
\hline page r ange & $207-212$ \\
\hline year & $2007-01-01$ \\
\hline URL & ht t p: //hdl . handl e. net /2297/6745 \\
\hline
\end{tabular}




\title{
The influence of the hot wire temperature on the crystallization of Mc-Si:H films prepared by hot wire-assisted-ECR-CVD
}

\begin{abstract}
We have constructed a hot wire assisted ECR CVD system to prepare a-Si:H and $\mu \mathrm{c}-\mathrm{Si}: \mathrm{H}$ films. The effect of hot wire temperature on crystallization of a-Si:H films is studied in the films prepared by these system. The crystalline fraction and crystalline grain size are analyzed by Raman scattering. The hydrogen content and the bonding scheme of hydrogen were measured by Fourier transform infrared (FTIR) spectroscopy. At low hot wire temperature, about 20 at.\% hydrogen is included in the film. With increasing the hot wire temperature, the total content of the hydrogen, $\mathrm{SiH}_{2}$ and $\mathrm{SiH}$ decrease and the microcrystalline phase appears. It is found from the ratio of the crystalline TO peak to the total area of the TO peak of the Raman scattering spectra that the volume fraction of the crystalline phase increases with increasing the hot wire temperature. The crystalline peak has a tendency to shift toward the higher wavenumber with increasing the hot wire temperature, suggesting that the grain size increases with increasing the hot wire temperature.
\end{abstract}

\section{INTRODUCTION}

In recent years the applications of hydrogenated microcrystalline silicon $(\mu \mathrm{c}-\mathrm{Si}: \mathrm{H})$ films, grown at low substrate temperature, in thin film transistors (TFT) for use in active matrix liquid crystal displays, p-i-n solar cells and light emitting devices (LED) have been intensively investigated. Light-induced degradation of a-Si:H based solar cells has been a major impediment in the development of thin film amorphous silicon technology. The stability of a-Si:H films is related to the amorphous network structure, whereas the improvement of amorphous network may finally lead to the formation of micro or nanocrystalline silicon ( $\mu \mathrm{c}$ - or $\mathrm{nc}-\mathrm{Si}$ ), which shows no noticeable light-induced degradation, but a poor photosensitivity. It has been confirmed in recent years that hydrogenated silicon films deposited in the regime just above the phase transition from amorphous to crystalline state could gain both the fine photoelectronic properties like a-Si:H and high stability like $\mu \mathrm{c}-\mathrm{Si}: \mathrm{H}$ [1-6]. The demand of these applications is not only a high quality but also a high deposition rate on the preparation. Although the plasma-enhanced CVD is commonly used for the preparation of $\mu \mathrm{c}-\mathrm{Si}: \mathrm{H}$, the electron cyclotron resonance (ECR) CVD and hot wire (HW) CVD have also been studied as promising methods to obtain a high rate deposition at low substrate temperature. We have constructed a hot wire assisted ECR CVD system to prepare a-Si:H and $\mu \mathrm{c}-\mathrm{Si}: \mathrm{H}$ films.

In this paper, a-Si:H and $\mu \mathrm{c}-\mathrm{Si}: \mathrm{H}$ films have been deposited at various hot wire temperature in a hot wire assisted MWECR CVD apparatus. The effect of hot wire temperature on crystallization of a-Si:H films is studied in the films prepared by the above system. 


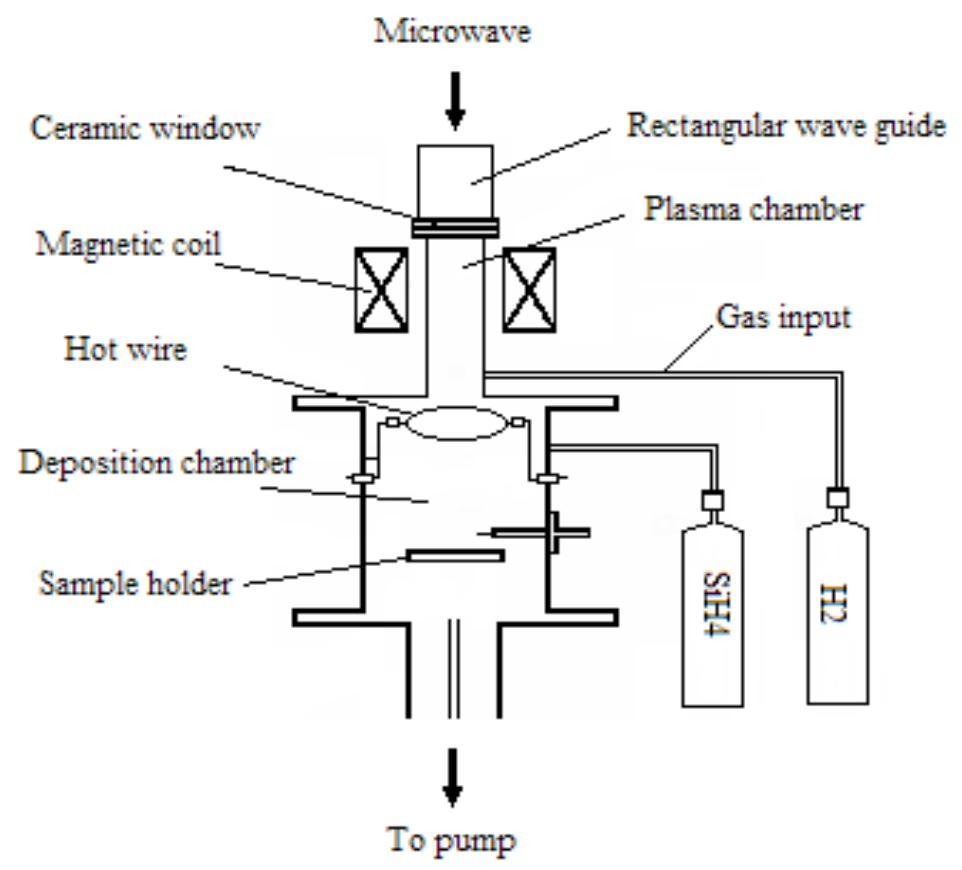

Fig.1. Schematic diagram of the experimental apparatus.

\section{EXPERIMENTAL DETAILS}

A-Si:H and $\mu \mathrm{c}-\mathrm{Si}: \mathrm{H}$ films were prepared using hot wire assisted MWECR CVD system. The schematic diagram of the experimental apparatus is shown in Figure 1. The frequency of the microwave was $2.45 \mathrm{GHz}$, the power was $555 \mathrm{~W}$ and the intensity of magnetic field in resonance section was $0.0875 \mathrm{~T}$. In order to increase the activity of the particles, we used hot wire assisted technique. The tungsten filaments of $0.5 \mathrm{~mm}$ thick and $350 \mathrm{~mm}$ long, located at about $60 \mathrm{~mm}$ from the substrate. The voltage in the filaments was controlled by a booster; the temperature of filament was measured by an infra-red pyrometer. The substrate temperature was $473 \mathrm{~K}$, pressure was $2 \mathrm{~Pa}$. The flow flux is $20 \mathrm{sccm}$, and the hydrogen dilution ratio is 1:4. The films were deposited on single crystal Si wafers and Corning-7059 glasses respectively. The film thickness was measured by a TENCOR alpha-step profilometer. The thickness of films was about $1 \mu \mathrm{m}$. The crystalline volume fraction and crystalline grain size are analyzed by Raman scattering. The hydrogen content and the bonding scheme of hydrogen were measured by Fourier transform infrared (FTIR) spectroscopy.

\section{RESULTS AND DISCUSSION}




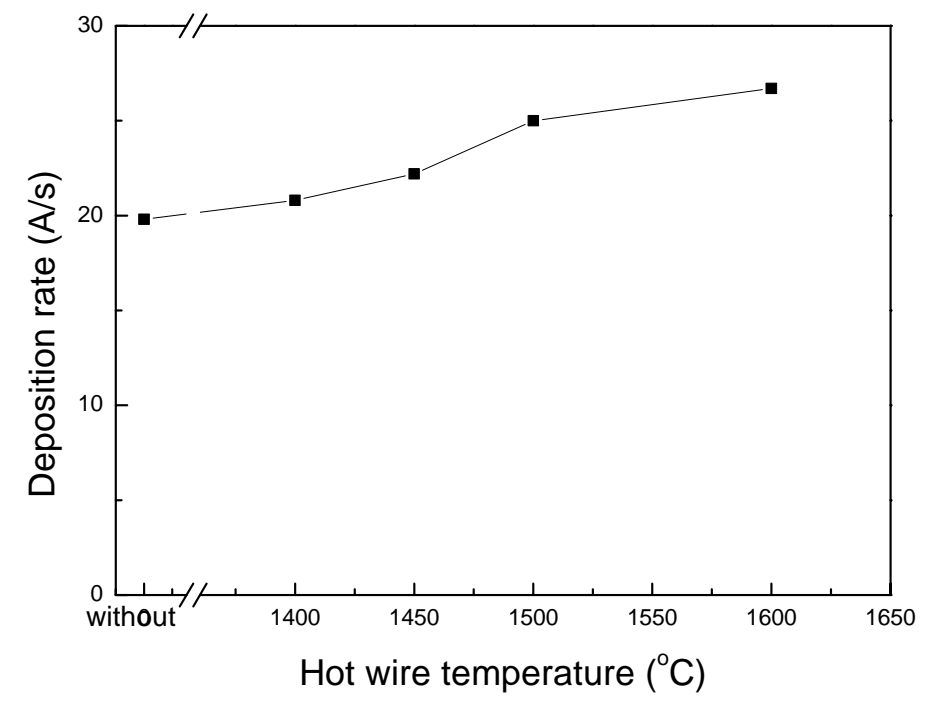

Fig. 2 Variation of deposition rate as a function of hot wire temperature of the films.

Figure 2 shows the variation of deposition rate as a function of the hot wire temperature. As seen in the figure, the deposition rate increases from 19.8 to $26.7 \AA / \mathrm{s}$, as the HW temperature increases up to $1600^{\circ} \mathrm{C}$. The deposition rates in the present work are much higher than those by the ECR CVD [7] and those by the HW CVD in the low HW temperature range [8].

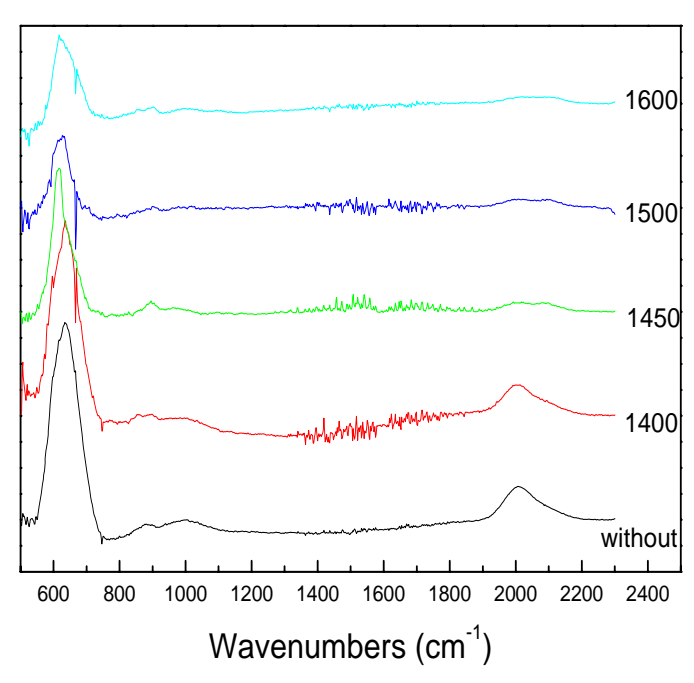

Fig. 3 (a) FTIR absorption

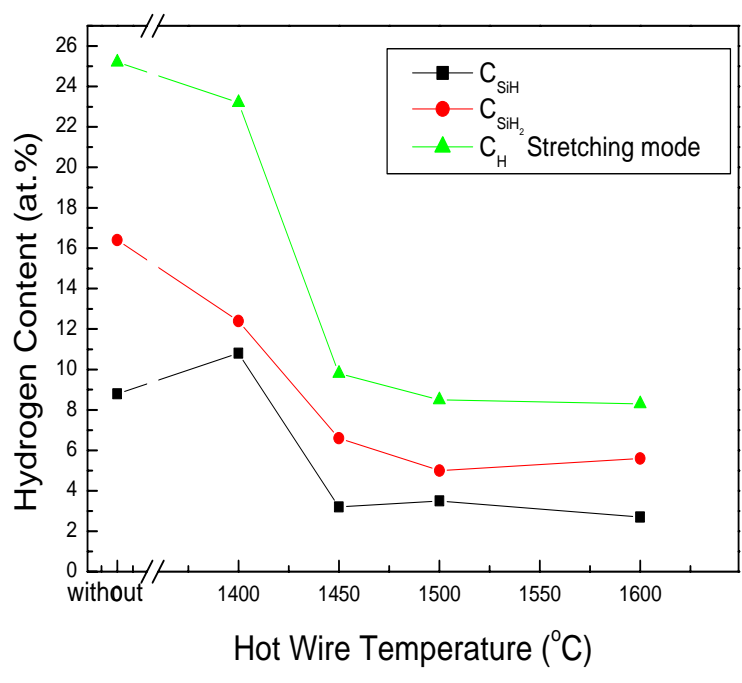

Fig. 3 (b) Hydrogen content of the 
The FTIR absorption spectra of the films are shown in Figure 3(a). Two peaks of the stretching mode of $\mathrm{SiH}$ and $\mathrm{SiH}_{2}$ were observed at $2000 \mathrm{~cm}^{-1}$ and $2100 \mathrm{~cm}^{-1}$, respectively. Two Gaussian peaks were used to fit the observed spectra. The amount of hydrogen bonded in $\mathrm{SiH}$ and $\mathrm{SiH}_{2}$ configurations $\left(\mathrm{C}_{\mathrm{SiH}}\right.$ and $\left.\mathrm{C}_{\mathrm{SiH}}\right)$ was calculated from the area of each assigned peak and the total content of hydrogen $\left(\mathrm{C}_{\mathrm{H}}\right)$ was the sum of $\mathrm{C}_{\mathrm{SiH}}$ and $\mathrm{C}_{\mathrm{SiH}}$. The hydrogen contents are shown in Figure 3(b). With increasing the hot-wire temperature, the total hydrogen content and the $\mathrm{SiH}_{2}$ content decrease, but the $\mathrm{SiH}$ content first increases and then decreases, and above the $1450^{\circ} \mathrm{C}$, the $\mathrm{SiH}$ content almost do not change.

Transverse optic (TO) modes of Raman spectra obtained from the $\mu \mathrm{c}-\mathrm{Si}: \mathrm{H}$ films prepared at various hot wire temperature are shown in Figure 4. As the hot-wire temperature increased, the c-Si TO peak (at around $520 \mathrm{~cm}^{-1}$ ) appears and increases. From Fig.4, it can be found that the crystalline peak has a tendency to shift toward the higher wavenumber with increasing the hot wire temperature, suggesting that the grain size increases with increasing the hot wire temperature.

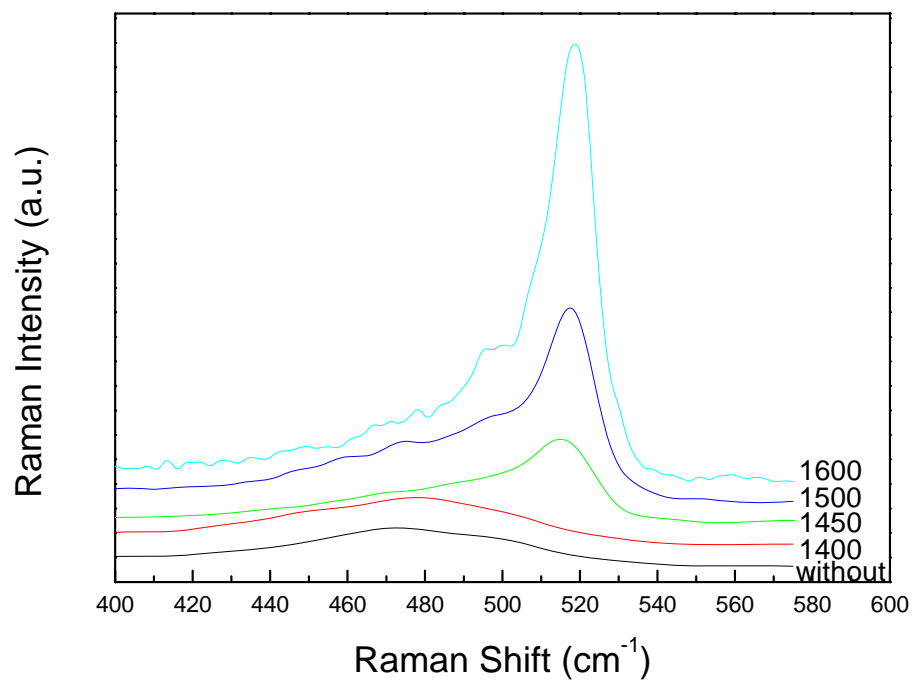

Fig. 4 Raman spectra of the films deposited with different hot-wire

The grain size and the volume crystalline fraction of the films can be deduced by using the TO mode. Assuming a confinement model, the Raman shift is related with the size L of the crystallite as the formula (1) [9]:

$$
\Delta \omega=\omega(\mathrm{L})-\omega_{0}=-\mathrm{A}(\mathrm{a} / \mathrm{L})^{\gamma}
$$

where $\omega(L)$ is the frequency of the Raman phonon with size $L, \omega_{0}$ is the frequency of the optical phonon at the zone center, and $a$ is the lattice constant of Si. The parameters $A$ and $\gamma$ used to describe the vibrational confinement are $47.41 \mathrm{~cm}^{-1}$ and 1.44, respectively. From Fig.4, $\Delta \omega$ is found to be $4.5 \mathrm{~cm}^{-1}, 2.5 \mathrm{~cm}^{-1}$ and $1.5 \mathrm{~cm}^{-1}$ for samples that with the hot wire temperature of $1450^{\circ} \mathrm{C}, 1500^{\circ} \mathrm{C}$ and $1600^{\circ} \mathrm{C}$, respectively. Then we obtain the corresponding grain size of $2.8 \mathrm{~nm}$, 
$4.2 \mathrm{~nm}$ and $6.0 \mathrm{~nm}$, respectively. The increase in the grain size may be affected by the change in the structural disorder in the amorphous phase which is correlated to the $\mathrm{SiH}$ bonding characteristics of the film.

In order to obtain the crystalline volume fraction $X c$, the Raman spectra of the TO mode were deconvolved into three components [10]. The lower wavenumber component (a) at around $480 \mathrm{~cm}^{-1}$ due to a-Si, the higher wavenumber component (c) at around $520 \mathrm{~cm}^{-1}$ due to c-Si and the intermediate component (b) at around $510 \mathrm{~cm}^{-1}$ due to the bond dilation at the grain boundaries. The crystalline volume fraction was deduced from the formula (2):

$$
X_{c}=\left(I_{b}+I_{c}\right) /\left(I_{a}+I_{b}+I_{c}\right)
$$

where $I_{a}, I_{b}$ and $I_{c}$ denote the intensity of the integrated intensity of the three components, respectively. It is found that the $X c$ of the $\mu \mathrm{c}-\mathrm{Si}: \mathrm{H}$ films is $53.6 \%, 60.3 \%$ and $78.2 \%$, which hot-wire temperature of $1450{ }^{\circ} \mathrm{C}, 1500{ }^{\circ} \mathrm{C}$ and $1600^{\circ} \mathrm{C}$, respectively.

The results mentioned above are quite different from those of the films synthesized by either HW CVD or ECR CVD method. The coverage over the growing surface with atomic hydrogen is required for the forming of micro crystallites because the adsorbed $\mathrm{SiH}_{3}$ can migrate to find a low energy site for crystallization when the growing surface is covered with hydrogen atoms [11]. In the case of HW CVD, the atomic hydrogen is supplied by the decomposition of $\mathrm{SiH}_{4}$ on the hot wire. Sufficient amounts of hydrogen atoms for the surface coverage as well as an amount of adsorbed $\mathrm{SiH}_{3}$ to keep the film deposition are attained when the $\mathrm{HW}$ temperature is high, e.g. $2100^{\circ} \mathrm{C}$ [8]. In the case of ECR CVD, however, a very high dilution rate of $\mathrm{H}_{2} / \mathrm{SiH}_{4}$ is used for preparation of the $\mu \mathrm{c}-\mathrm{Si}: \mathrm{H}$. Moreover, a high microwave power $\mathrm{P}_{\mathrm{mw}}$ is needed to get the surface coverage with hydrogen atoms and a high substrate temperature $T_{\mathrm{s}}$ is needed to make adsorbed $\mathrm{SiH}_{3}$ migrate on the growing surface, for example, $\mathrm{P}_{\mathrm{mw}} \geq 540 \mathrm{~W}$ and $\mathrm{T}_{\mathrm{s}} \geq 250^{\circ} \mathrm{C}$ [7]. We can prepare $\mu \mathrm{c}-\mathrm{Si}: \mathrm{H}$ at lower HW temperatures than by the HW CVD and at lower dilution ratio, $\mathrm{P}_{\mathrm{mw}}$ and $\mathrm{T}_{\mathrm{s}}$ than by the ECR CVD.

It is reported for a-Si:H films prepared by HW CVD that the deposition rate dramatically increases and the hydrogen content increases with the HW temperature [8]. In the present work, however, the deposition rate increases slightly with the HW temperature as shown in Fig. 2 and the hydrogen content decreases with the HW temperature as shown in Fig. 3(b). The rather high deposition rate in the a-Si:H film deposited with $\mathrm{T}_{\mathrm{w}} \leq 1400^{\circ} \mathrm{C}$ in present work compared to ref. 8 can be attributed to the enhancement by the effect of ECR. The atomic hydrogen created in the ECR chamber may enhance the decomposition of $\mathrm{SiH}_{4}$ to increase the decomposition rate. Both the films prepared without operating $\mathrm{HW}$ and those prepared with $\mathrm{T}_{\mathrm{w}}=1400^{\circ} \mathrm{C}$ are in the amorphous phase. But the latter films have a higher concentration of hydrogen atoms in the monohydride phase in spite of the lower concentration of total bonded hydrogen atoms than the former films as shown in Fig. 3(b). This suggests that not only the hydrogen atoms originating from the ECR plasma but also those created by HW contribute to yield a good quality a-Si:H. At higher HW temperature $\left(\geq 1450^{\circ} \mathrm{C}\right)$, micro crystallites appear in the films. The excess atomic hydrogen may attack the growing surface of the film and have an etching effect and so the deposition rate decreases, but the overall deposition rate increases under the competition between the decomposition and the etching. Because of the etching effect, the hydrogen content in the films tends to decrease with increasing the HW temperature as shown in Fig. 3(b). 


\section{CONCLUSIONS}

The effect of hot wire temperature on the properties of $\mu \mathrm{c}-\mathrm{Si}: \mathrm{H}$ was studied. The deposition rate of the samples dependent on the hot wire temperature. The total hydrogen content of the films showed a tendency to decrease with the hot wire temperature increasing. The hydrogen content of $\mathrm{SiH}$ first increases and then decreases with the hot wire temperature increasing. And from $1450^{\circ} \mathrm{C}$, microcrystalline silicon phase appears. With increasing the hot wire temperature, crystalline volume fraction and crystalline grain size increase. Microcrystallization to the $\mathrm{Si}: \mathrm{H}$ network has been easily obtained from the hot wire assisted ECR CVD method at a relatively low power, low substrate temperature and low hot wire temperature.

\section{ACKNOWLEDGEMENT}

The author expresses her great thanks to many colleagues for valuable assistance in the experiments and discussions. In particular, she is grateful to Prof. A. Morimoto and Dr. T. Kawae

of Kanazawa University. Part of this work has been supported by the State Key Development Program for Basic Research of China.

\section{REFERENCES}

1. M. Medudre, R. Meaudre, R. Butte', S. Vignoli, J. Appl. Phys. 86, 946 (1999).

2. P. Roca I Cabarrocas, A. Fontcuberta i Morral, Y. Poissant, Thin Solid Films 39, 403 (2002).

3. P. M. Voylesa, J. Appl. Phys. 90, 4437 (2001).

4. J. M. Pearce, R. J. Koval, A. S. Ferlauto, R. W. Collins, C. R. Wronski, Appl. Phys. Lett. 77, 3093 (2000).

5. C. Das, S. Ray, Thin Solid Films 81, 403 (2002).

6. S. Sheng, X. Liao, G. Kong, Appl. Phys. Lett. 73, 336 (1998).

7. S. Ferrero, P. Mandracci, G. Cicero, F. Giorgis, C.F. Pirri, G. Barucca, Thin Solid Films 383, $181(2001)$.

8. S. R. Jadkar, J.V. Sali, S.T. Kshrisagar, M. G. Takwale, Thin Solid Films 437, 18 (2003).

9. Jian Zi, H. Buscher, C. Falter, W. Ludwig, Kaiming Zhang and Xide Xie, Appl. Phys. Lett. 69 (2), 8 (1996).

10. M. Vanacek, J. Kocka, J. Strichlik, Z. Kosicek, O. Stika, A. Triska, Sol. Energy Mater. 8, 411 (1983).

11. Akihisa Matsuda, Jan.J.Appl.Phys. 43, 7909 (2004). 